\title{
The potential of a new rigid-rod polymer fibre ('M5') in advanced composite structures
}

\author{
O.C. van der Jagt ${ }^{\mathrm{a}, *}$, A. Beukers ${ }^{\mathrm{b}}$ \\ advanced LightWeight Engineering B.V., Delft, The Netherlands \\ ${ }^{\mathrm{b}}$ Delft University of Technology, Department of Aerospace Engineering, Structures and Materials Laboratory, Centre of Lightweight Structures, Delft, \\ The Netherlands
}

Received 2 September 1997; revised 25 February 1998; accepted 26 March 1998

\begin{abstract}
AKZO NOBEL has developed a new rigid-rod polymer fibre called M5. This new fibre offers high (specific) tensile and compressive mechanical properties, good adhesive bonding with common thermosetting resins, good chemical resistance and a broad useful temperature range up to $600^{\circ} \mathrm{C}$. Advanced LightWeight Engineering, in co-operation with the Structures and Materials Laboratory, Faculty of Aerospace Engineering, Delft University of Technology, executes research on composites with this new fibre as reinforcement. The main goals of the research are to establish mechanical properties of M5 composites and to identify attractive applications for M5 composites. This research led to the following conclusions. M5 outclasses most other engineering fibres and its compressive strength must be considered high for a polymeric fibre, with values as high as $1750 \mathrm{MPa}$ derived from three-point bending tests. M5 is suited for use in special products, for which carbon fibres cannot be used, or where the application of M5 offers a significant advantage. Examples of such products are: LPG tanks, drive shafts, Side Impact Protection Beams for cars and Fibre Metal Laminates. M5 can also be used in any other product currently made with carbon fibre composites, except those which exploit the electrical and/or thermal conductivity of carbon fibres. (C) 1998 Elsevier Science Ltd. All rights reserved.
\end{abstract}

Keywords: Rigid-rod polymer fibre; Composite structures

\section{Introduction}

Fibre-reinforced materials, also known as composites ${ }^{1}$, consist of reinforcing fibres embedded in a matrix. The main function of the fibres is to carry load, while the main function of the matrix material is to transfer load from one fibre to another, thus distributing the load throughout the material and structure. The mechanical properties of the fibre-reinforced material are normally dominated by the mechanical properties of the reinforcing fibres, though the adhesive bonding of the fibres to the matrix is also important.

Fibre-Reinforced Plastics (FRP), which consist of fibres in a polymer-based matrix, can be classified by different criteria. One of them is the length of reinforcing

\footnotetext{
* Corresponding author.

${ }^{1}$ A composite material (in the broadest sense of the word) is a combination of any two or more other materials. This means that a composite material not necessarily has to consist of fibre material embedded in matrix material. Therefore, every fibre-reinforced material is a composite, but not all composites are fibre-reinforced materials
}

fibres. Normally, a distinction is made between short and continuous fibres. The longer the fibres, the higher the mechanical properties of the FRP made from these fibres can be. In this article, only FRPs reinforced with continuous fibres are considered.

Nowadays, advanced FRP offer the possibility of creating low mass, stiff, strong and durable structures. These properties are highly desirable in the transport industry and many other fields, e.g. in sports, where a low mass improves performance.

Since fuel prices rise and environmental issues become more dominant, mass reduction for motorised vehicles becomes more and more important [1]. Besides, safety requirements are getting more severe in all ranges of transportation. Finally, competitive selling prices, low maintenance costs and repairability are important and desirable economical features.

In other fields, e.g. in civil engineering, off-shore and the petrochemical sector, mass reduction is not of prime importance. An increase in life-time, and a reduction of maintenance and production costs are the driving forces to introduce FRP. 
Table 1

Compressive strength of aramid, PBO and UHMWPE fibres

\begin{tabular}{ll}
\hline aramid & $<300 \mathrm{MPa}$ \\
PBO & $<280 \mathrm{MPa}$ \\
UHMWPE & $<50 \mathrm{MPa}$ \\
\hline
\end{tabular}

These growing demands in all fields impose challenging tasks on the FRP designers.

Therefore, designers require materials that offer high specific mechanical properties at an acceptable price level. They can choose from a wide range of fibre and matrix materials. The growing requirements for structures and the competitive market, however, offer possibilities for new advanced fibre and resin materials. Two mechanical properties are of prime importance to the FRP designer, i.e. stiffness and strength.

A high stiffness is important for lightweight structures, which are normally slender, thin-walled structures, and thus sensitive for local and global buckling.

Besides, a high stiffness is required to obtain structures that are dimensionally stable under mechanical loading. For instance, aircraft structures need to be stiff to avoid unwanted dynamic coupling between the applied aerodynamic load and the structure's response, which can cause the aircraft to be uncontrollable or can result in structural failure.

A high strength is required to obtain structures which withstand high mechanical loads without failure. Compressive strength is also important in that respect.

Currently, two other polymeric engineering ${ }^{2}$ fibre materials are commercially available: aramid fibres (trade names Twaron, Kevlar, Technora) and UHMWPE fibres (trade names Dyneema, Spectra). A third polymeric fibre material is emerging slowly: PBO fibres (trade name Zylon). All these polymeric fibres show poor compressive strength (Table 1).

AKZO NOBEL has developed a new fibre: a rigid-rod polymer fibre (poly\{2,6-diimidazo[4,5-b:4' $5^{\prime}$-e]pyridinylene-1,4(2,5-dihydroxy)phenylene\} abbreviated as PIPD and routinely referred to as M5 in this paper) with a bidirectional intermolecular hydrogen-bonded network. Fibres spun from the new polymer show very good tensile mechanical properties (Table 2). Besides, it was expected that the hydrogen bonds have a positive effect on the fibre compressive strength ${ }^{3}$.

To establish the mechanical properties of FRP's with M5, research has been executed on M5/epoxy composites.

The goals of the research at the Structures and Materials Laboratory on the new M5 fibre are:

1. To establish mechanical properties of the new M5 fibre on a composite level, starting with the one property that is considered the most important flaw in current polymeric fibres: compressive strength.

\footnotetext{
${ }^{2}$ Engineering fibres are used in load carrying structures and their main function is to carry external mechanical loading.

${ }^{3}$ See accompanying paper by DJ Sikkema.
}

Table 2

Current M5 tensile mechanical properties and density

\begin{tabular}{ll}
\hline$E$ & $330 \mathrm{GPa}$ \\
$\sigma_{\mathrm{t}}$ & $4000 \mathrm{MPa}$ \\
$\epsilon_{\mathrm{t}}$ & $1.5 \%$ \\
$\rho$ & $1700 \mathrm{~kg} / \mathrm{m}^{3}$ \\
\hline
\end{tabular}

$E=$ Young's modulus; $\sigma=$ maximum stress; $\epsilon=$ maximum strain; subscript $\mathrm{c}=$ compression; subscript $\mathrm{t}=$ tension.

2. To determine the consequences of the measured results on designing with M5 composites.

3. To identify attractive applications for M5 composites.

The M5 fibre is only available in small quantities and is produced batchwise on a laboratory scale. As a consequence, the mechanical tests that have been executed so far have a preliminary character. First, because the quality of the M5 fibre improves constantly, and so the production process is improved continuously. Secondly, because only a limited amount of M5 per batch is available, only a few test samples per batch could be manufactured and tested.

\section{Mechanical tests on UD M5/epoxy composites}

\subsection{Compressive properties}

Six batches of M5 have been tested to determine the compressive mechanical properties of UD M5/epoxy composites. Tests were executed according to DIN 65380 . The results of this standard are comparable with results of tests according to ASTM D3410-87. The samples were manufactured by filament winding around a flat plate $(500 \mathrm{~mm}$ long and $6.35 \mathrm{~mm}$ wide). Strains were measured by strain gauges applied to both sides of the specimen, and the mean value is taken to rule out any bending effects (Table 3).

The measured compressive modulus agreed well with the tensile modulus, as provided by AKZO NOBEL. Values varying from 0.84 to 1.03 times the tensile modulus (varying from $240 \mathrm{GPa}$ to $351 \mathrm{GPa}$ ) were measured. The slightly lower values can be explained by void content of the laminates and fibre misalignments.

The maximum compressive stress was lower than the maximum tensile stress. Typical values were 0.16-0.22 times the maximum tensile stress, with absolute values as

Table 3

M5 specimen and fibre characteristics for compressive tests

\begin{tabular}{llllll}
\hline \multicolumn{3}{c}{ Fibre tensile properties } & \multicolumn{2}{c}{ Specimen properties } \\
$\begin{array}{l}\text { M5 batch- } \\
\text { number }\end{array}$ & $E(\mathrm{GPa})$ & $\sigma(\mathrm{MPa})$ & $\epsilon(\%)$ & Matrix & $V_{\mathrm{f}}$ \\
\hline 1 & & & & & \\
2 & 265 & 2720 & 1.06 & epoxy & 0.62 \\
3 & 240 & 2210 & 0.95 & epoxy & 0.48 \\
4 & 287 & 3665 & 1.31 & epoxy & 0.49 \\
5 & 294 & 3494 & 1.23 & epoxy & 0.53 \\
6 & 351 & 3245 & 1.42 & epoxy & 0.69 \\
& & 3444 & 0.97 & epoxy & 0.62 \\
\hline
\end{tabular}




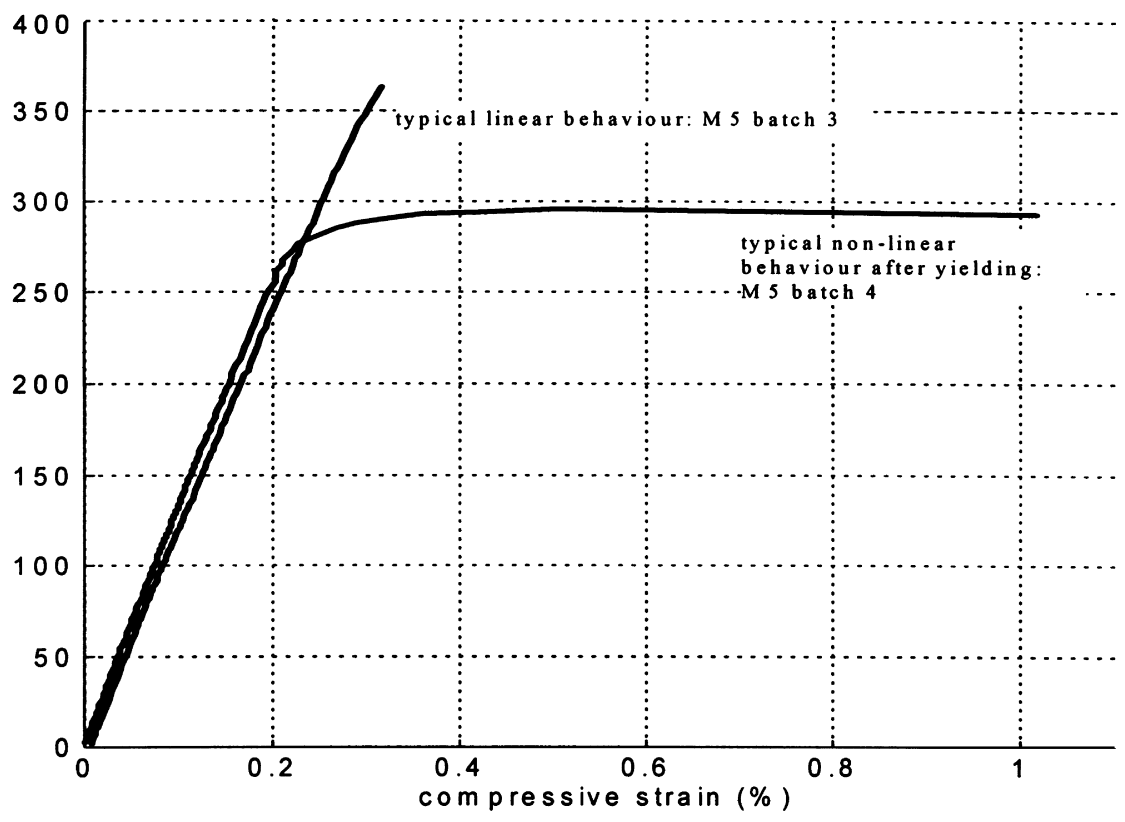

Fig. 1. Typical compressive stress-strain curves of an UD M5/epoxy.

high as $800 \mathrm{MPa}$ on fibre level. These values must be considered high for a polymeric fibre (compare aramid $<300 \mathrm{MPa}$ and PBO $<280 \mathrm{MPa})$.

The linear elastic compressive strain was found to be $0.2-0.3 \%$. Striking was the 'plastic' (or non-linear) behaviour of several M5 composites, showing maximum compressive strains up to $1 \%$. This was in sharp contrast to the brittle failure mode of CRFP, which showed no 'plastic' behaviour at all, and failed suddenly.

The measured maximum compressive strains depended greatly on the failure point of the specimen. Several failure points were observed. Fig. 1 shows some typical compressive stress-strain curves.

Failure usually occurred in a shear mode, with the shear plane about $45^{\circ}$ to the fibre direction. Normally, polymeric fibres, e.g. aramid fibres, fail in compression due to the formation of kink bands ('micro-buckling'). Surprisingly, SEM pictures of failed specimen revealed hardly any kink bands on the M5 fibre. This phenomenon is not yet understood (Table 4).

\subsection{Residual strength of UD M5/epoxy composites with compressive damage}

Residual strength can be defined as the capability of a structure to carry load after the structure has sustained damage. In this case, the damage consisted of loading the specimen to failure in compression. Two types of residual strength can be considered, i.e. residual compressive strength and residual tensile strength.

\subsubsection{Residual compressive strength}

Fig. 2 is a typical force-displacement curve showing great residual compressive strength after compressive failure (Table 5).

The residual compressive strength of UD M5/epoxy composites varies from 0.41 to 0.62 times the original compressive strength, even up to such large deformations as $38 \%$. Of course, the stiffness of the composite is about zero ('viscous flow behaviour'). This behaviour is unequalled by CFRP (Fig. 3).

Table 4

Summary of results of compressive tests according to DIN 65380 on UD M5/epoxy composites on fibre level and comparison with tensile properties as supplied by AKZO NOBEL

\begin{tabular}{|c|c|c|c|c|c|c|c|c|c|}
\hline $\begin{array}{l}\text { Material batch } \\
\text { number }\end{array}$ & $E_{\mathrm{t}}(\mathrm{GPa})$ & $E_{\mathrm{c}}(\mathrm{GPa})$ & $\sigma_{\mathrm{t}}(\mathrm{MPa})$ & $\sigma_{\mathrm{c}}(\mathrm{MPa})$ & $\epsilon_{\mathrm{t}}(\%)$ & $\epsilon_{\mathrm{c}}(\%)$ & $E_{\mathrm{c}} / E_{\mathrm{t}}$ & $\sigma_{\mathrm{c}} / \sigma_{\mathrm{t}}$ & $\epsilon_{\mathrm{c}} / \epsilon_{\mathrm{t}}$ \\
\hline 1 & 265 & $232 \pm 42$ & 2720 & $605 \pm 46$ & 1.06 & $0.28 \pm 0.02$ & 0.87 & 0.22 & 0.26 \\
\hline 2 & 240 & $238 \pm 9.6$ & 2210 & $491 \pm 10$ & 0.95 & $0.23 \pm 0.03$ & 0.99 & 0.22 & 0.24 \\
\hline 3 & 287 & $257 \pm 9.4$ & 3665 & $665 \pm 68$ & 1.31 & $0.26 \pm 0.03$ & 0.90 & 0.18 & 0.20 \\
\hline 4 & 294 & $248 \pm 5.6$ & 3494 & $562 \pm 27$ & 1.23 & $0.61 \pm 0.29$ & 0.84 & 0.16 & 0.31 \\
\hline 5 & 250 & $257 \pm 10.2$ & 3245 & $556 \pm 41$ & 1.42 & $0.22 \pm 0.02$ & 1.03 & 0.17 & 0.16 \\
\hline 6 & 351 & $312 \pm 12.4$ & 3444 & $761 \pm 47$ & 0.97 & $0.25 \pm 0.01$ & 0.89 & 0.22 & 0.25 \\
\hline
\end{tabular}


compressive force

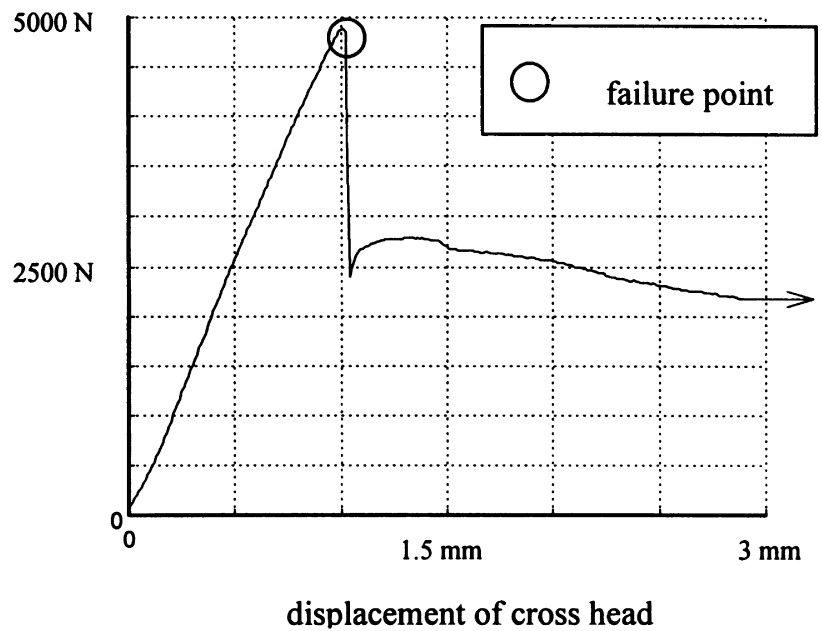

Fig. 2. Typical force-displacement curve of UD M5/epoxy composite in compressive DIN 65380 test.

\subsubsection{Residual tensile strength}

UD M5/epoxy composites showed a residual tensile strength varying from 0.13 to 0.27 times the original tensile strength, and still showing a considerable modulus. The residual tensile strength seems not to depend on the applied compressive deformation or original compressive strength (Table 6).

\subsection{Influence of water absorption on the compressive mechanical properties}

Another issue that is investigated preliminarily, is the influence of water absorption on the compressive mechanical properties of M5. Due to the limited amount of M5 available, only eight samples are tested.

Preliminary tests showed an almost linear relation between the tensile modulus measured beforehand (representing the quality of the fibre) and the water absorption ${ }^{4}$ (Fig. 4).

Much more of interest than this relation is the influence of

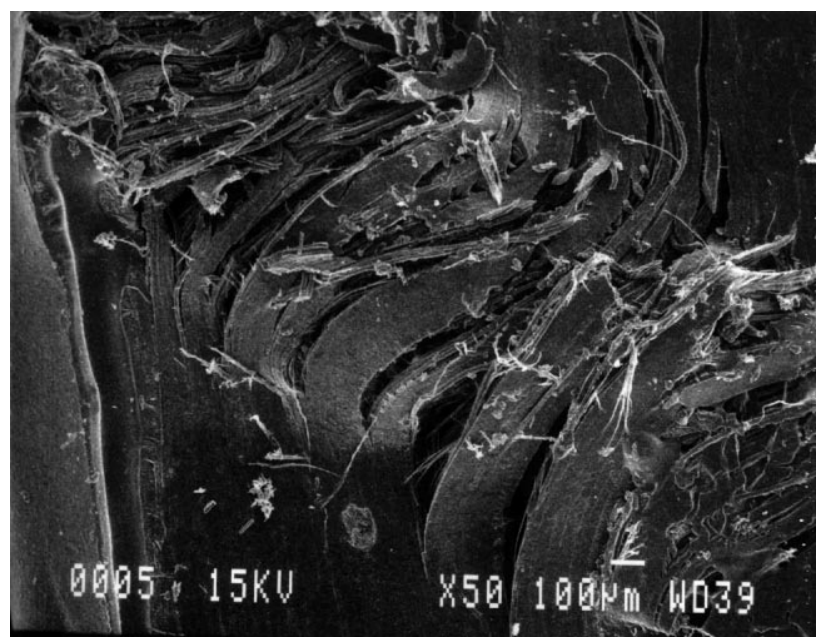

Fig. 3. SEM picture of UD M5 L2108A0103/epoxy specimen showing severe compressive deformation (25\%). This specimen was still able to carry on 0.4 times the compressive failure load.

water absorption on the mechanical properties of M5/epoxy composites. The moist specimens were also tested according to DIN 65380 and the results compared with the data of the dry specimen. No significant decrease in compressive strength was observed. For six specimens, even an increase (up to 1.1 times the dry compressive strength) in compressive strength was measured. During testing, no behaviour different from the previous tests was observed. The force-displacement curves indicate no significant difference in E-modulus (Table 7).

The conclusion of this test is that water absorption has no or some beneficial effect on the compressive strength of UD M5/epoxy laminates.

\subsection{Three-point bending tests}

Compressive tests, e.g. DIN 65380 and ASTM D3410, are currently subject to discussion [2]. The resulting data show a large scatter (50-100\% depending on the test method). This is due to the fact that global and local

Table 5

Summary of results of residual compressive strength after compressive failure

\begin{tabular}{|c|c|c|c|c|c|}
\hline M5 batch number & Sample \# & $\begin{array}{l}\text { Compressive deformation } \\
\text { (damage) }(\%)\end{array}$ & $\begin{array}{l}\text { Compressive } \\
\text { strength (MPa) }\end{array}$ & $\begin{array}{l}\text { Residual compressive } \\
\text { strength }(\mathrm{MPa})\end{array}$ & Ratio \\
\hline 3 & 2 & 13 & 353.3 & 199.2 & 0.56 \\
\hline \multirow[t]{3}{*}{4} & 1 & 18 & 295.4 & 155.6 & 0.53 \\
\hline & 3 & 38 & 308.3 & 126.8 & 0.41 \\
\hline & 5 & 7 & 279.1 & 144.6 & 0.52 \\
\hline \multirow[t]{2}{*}{5} & 1 & 25 & 403.2 & 264.0 & 0.65 \\
\hline & 3 & 13 & 403.0 & 244.6 & 0.61 \\
\hline \multirow[t]{3}{*}{6} & 1 & 6 & 505.6 & 273.9 & 0.54 \\
\hline & 3 & 10 & 472.3 & 258.6 & 0.55 \\
\hline & 4 & 24 & 516.4 & 300.1 & 0.58 \\
\hline
\end{tabular}

\footnotetext{
${ }^{4}$ M5 fibre data based on immersion of M5 composite material.
} 
Table 6

Summary of results of residual tensile strength after compressive failure

\begin{tabular}{|c|c|c|c|c|c|}
\hline M5 batch number & Sample\# & $\begin{array}{l}\text { Compressive deformation } \\
\text { (damage) }(\%)\end{array}$ & $\begin{array}{l}\text { Tensile } \\
\text { strength }^{a}(\mathrm{MPa})\end{array}$ & $\begin{array}{l}\text { Residual tensile } \\
\text { strength }(\mathrm{MPa})\end{array}$ & Ratio \\
\hline \multirow[t]{4}{*}{3} & 1 & $<1$ & 1796 & 408.8 & 0.23 \\
\hline & 2 & 13 & 1796 & 377.6 & 0.21 \\
\hline & 4 & $<1$ & 1796 & 422.7 & 0.24 \\
\hline & 5 & $<1$ & 1796 & 479.7 & 0.27 \\
\hline \multirow[t]{3}{*}{4} & 1 & 18 & 1852 & 243.2 & 0.13 \\
\hline & 3 & 38 & 1852 & 280.6 & 0.15 \\
\hline & 5 & 7 & 1852 & 337.8 & 0.18 \\
\hline \multirow[t]{2}{*}{5} & 1 & 25 & 2239 & 381.7 & 0.17 \\
\hline & 6 & $<1$ & 2239 & 482.8 & 0.22 \\
\hline \multirow[t]{3}{*}{6} & 1 & 6 & 2135 & 497.4 & 0.23 \\
\hline & 3 & 10 & 2135 & 407.3 & 0.19 \\
\hline & 4 & 24 & 2135 & 479.3 & 0.22 \\
\hline
\end{tabular}

${ }^{a}$ Calculated with netting theory.

buckling phenomena play an important role in the failure mechanism, and it is difficult to achieve failure in pure compression. Specimen quality, and especially adhesive bonding between the fibre and matrix, is important in this respect.

To partly overcome these problems, three-point bending tests have been executed to establish the compressive mechanical properties of UD M5/epoxy composite indirectly.

Two batches of M5 have been tested to determine the three-point flexural mechanical properties of UD M5/ epoxy composites. Tests were executed according to ASTM D790-87M. Again, the samples were manufactured by filament winding around a flat plate $(500 \mathrm{~mm}$ long and $25 \mathrm{~mm}$ width) (Table 8).

The ASTM D790M standard provides a method of calculating the stresses and strains at the upper and lower part of the specimen from the force and displacement data. The given equations, however, are only valid in the linear elastic region of the force-displacement curve (Linear Bending Theory). This is not mentioned in the ASTM standard and the equations are used throughout the entire force-displacement curve, both in the linear and non-linear part. Of course, this gives inaccurate results for the calculated stresses and strains for the non-linear part of the force-displacement curve. To overcome this, another calculation method is used, based on the Plastic Bending Theory. A very short description of the Plastic Bending Theory, especially suited for use in calculations on composites showing 'ideal' elastic/plastic behaviour in compression (Fig. 1: M5 batch 4) can be found in the Appendix.

A typical force-displacement curve is shown in Fig. 5.

The average measured modulus was somewhat lower than expected, about 0.9 times the calculated value based on AKZO NOBEL fibre data. Average compressive yield strain was found to be about $0.45 \%$, with values as high as $0.5 \%$. This value is much higher than measured in the DIN 65380 compression test $(0.2-0.3 \%)$. The reason for this is that in the pure compression tests (local- and shear-) buckling phenomena (and therefore adhesive bonding between

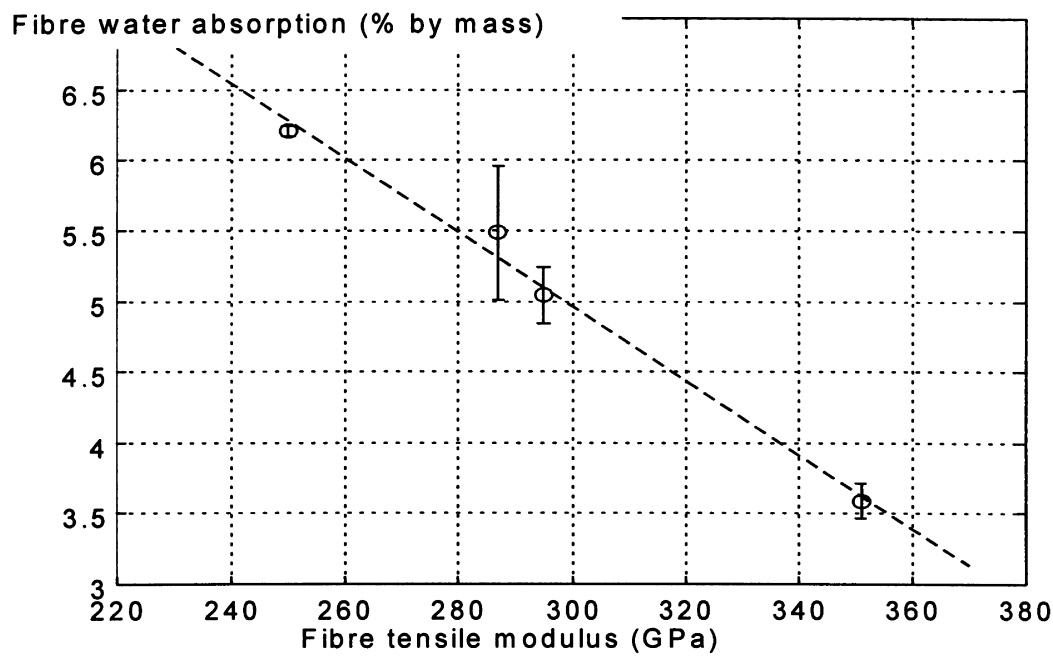

Fig. 4. M5 water absorption after seven days immersion in distilled water. 
Table 7

Effect of moisture on UD M5/epoxy compressive strength (seven days immersion in water at RT)

\begin{tabular}{|c|c|c|c|c|c|}
\hline M5 batch number & $V_{\mathrm{f}}$ & $\begin{array}{l}\text { Laminate moisture } \\
\text { content ( } \% \text { by mass) }\end{array}$ & $\begin{array}{l}\text { Original compressive } \\
\text { strength }(\mathrm{MPa})\end{array}$ & $\begin{array}{l}\text { Moist compressive } \\
\text { strength }(\mathrm{MPa})\end{array}$ & Ratio \\
\hline 3 & 0.49 & 3.5 & 325.9 & $351.3 \pm 17$ & 1.07 \\
\hline 5 & 0.69 & 5.0 & 384.0 & $407.5 \pm 28$ & 1.06 \\
\hline 6 & 0.62 & 2.7 & 486.9 & $427.7 \pm 58$ & 0.88 \\
\hline
\end{tabular}

the fibre and matrix) play a much more pronounced role. One can say that the three-point bending test gives a more realistic ${ }^{5}$ value.

It was not clear if ultimate failure occurred at the tensile or compressive side of the sample. Results calculated with the Plastic Bending Theory suggested that ultimate failure occurred at the tensile side of the sample in some cases (Table 9).

Another striking fact is that after the test, the specimens were deformed, but still in one piece with some load carrying capabilities. UD M5 laminates show a very favourable 'plastic' behaviour in compression and bending. These phenomena indicate that it is possible to design structures that are damage resistant and damage tolerant ${ }^{6}$. For transport vehicles, this infers that the crash worthiness increases $^{7}$.

\section{Potential applications for composites based on the new M5 fibre}

For designers of lightweight structures, specific stiffness

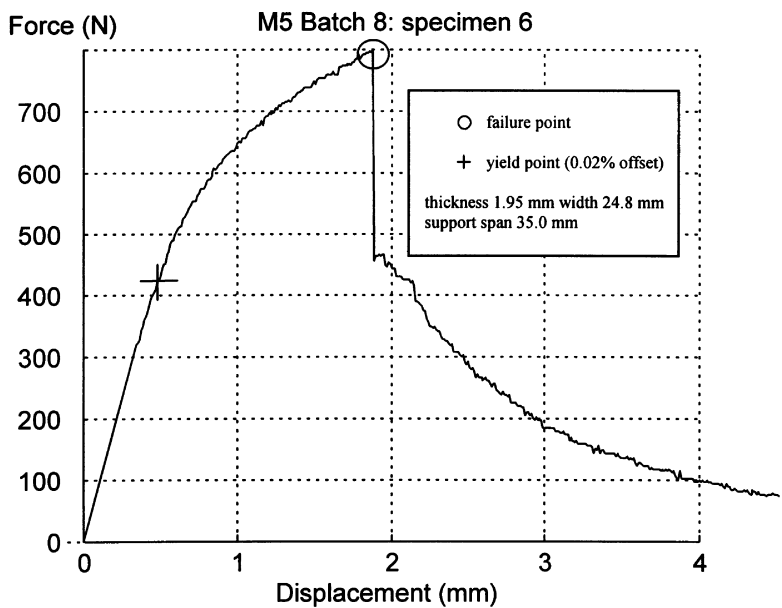

Fig. 5. Typical three-point bending (ASTM D790M) force-displacement curve on UD M5/epoxy laminates.

\footnotetext{
${ }^{5}$ Realistic in this case means that the compressive strength derived from the three-point bending test is most of the time more significant for the designer than that based on the pure ompression test.

${ }^{6}$ This means that properly designed structures made out of M5 composites show, when exposed to damage, a great residual strength.

${ }^{7}$ This means that properly designed vehicles with (part of) their structure made out of M5 composites, offer their passengers a greater chance of survival in the case of a crash.
}

and strength (stiffness and strength per unit weight) are important properties (Fig. 6).

\subsection{Structural efficiency}

Materials can be compared on pure mechanical properties alone. This comparison is not always meaningful. It is better to compare material properties on a component level [3]. A way of achieving this is to compare structural efficiencies of materials. The structural efficiency of a structure is defined by: structural efficiency $\equiv \frac{\text { performance of the structure }}{\text { mass of the structure }}$

Lightweight structures are normally thin-walled and slender structures, critical for failure in a local or global buckling mode when loaded in compression. For every load case, the structural efficiency parameter can be determined. In the case of a structure that is critical for global buckling, it can be calculated that the structural efficiency is a function of $\sqrt{ } E / \rho^{8}$.

The structural efficiency of such a structure is calculated for several materials (Fig. 7).

A high structural efficiency is one of the keys to costeffective structures. M5 composite structures can be more than 4.5 times as efficient than steel structures.

\subsection{Applications}

It is clear that M5 offers FRP designers possibilities to design efficient and cost-effective structures. Examples of those structures are:

1. A full-composite, wheel-shaped LPG pressure vessel (burst pressure 70 bar; $230-370 \mathrm{~K}$ ). A drawback in the use of LPG for small city cars is the LPG container, which still often is a cylindrical steel container. This container is heavy and takes up a lot of volume from

Table 8

M5 specimen and fibre characteristics for three-point bending tests

\begin{tabular}{llllll}
\hline & \multicolumn{2}{l}{ Fibre tensile properties } & \multicolumn{2}{c}{ Specimen properties } \\
M5 batch & $E(\mathrm{GPa})$ & $\sigma(\mathrm{MPa})$ & $\epsilon(\%)$ & Matrix & $V_{\mathrm{f}}$ \\
number & & & & & \\
\hline 7 & 312 & 3694 & 1.22 & epoxy & 0.23 \\
8 & 304 & 3021 & 1.01 & epoxy & 0.22 \\
\hline
\end{tabular}

\footnotetext{
${ }^{8} E$ is the material's Young's modulus; $\rho$ is material density.
} 


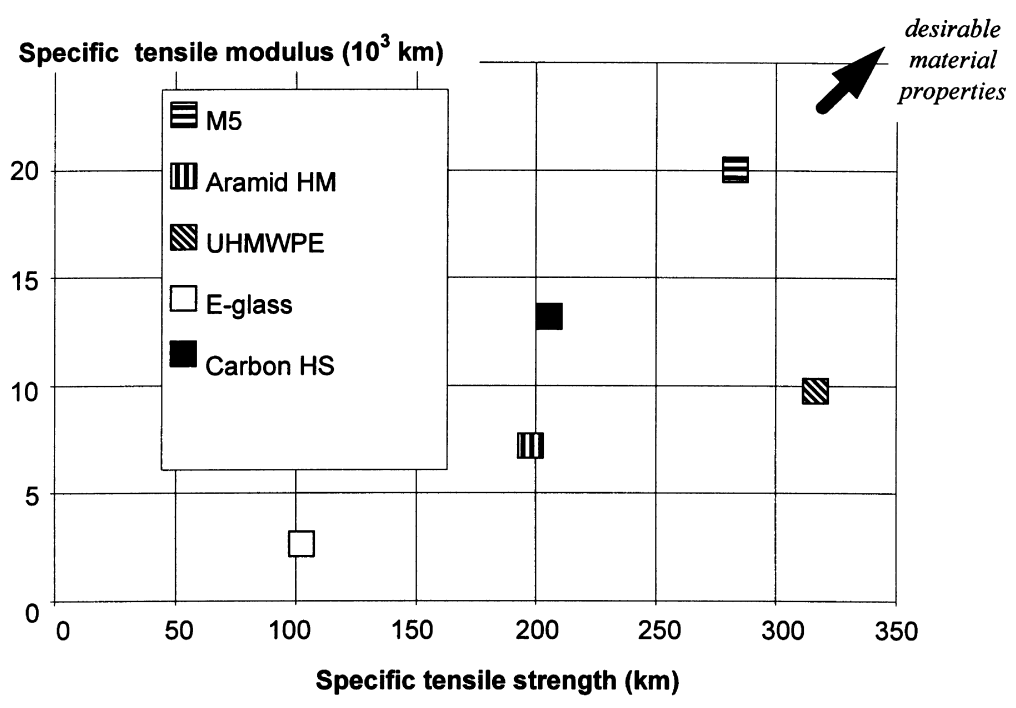

Fig. 6. Specific tensile mechanical properties of common engineering fibres.

the baggage compartment. A wheel-shaped container, to be fitted in the spare-wheel compartment, would be a better option. A filament-wound, M5 composite LPG container can be manufactured, which has a mass of about $1 / 10$ of an equivalent steel container. M5 is especially suited for this application because of its good mechanical properties and high temperature resistance.

2. A liquid oxygen container ( $100 \mathrm{bar} ; 77 \mathrm{~K}$ ), to be used in a hybrid rocket engine. In this case, the high specific strength and stiffness, combined with its thermal insulating properties, offer great advantages compared with other engineering composites, resulting in a reduced mass and reduced production time.

3. Thermal insulating support straps for cryogenic applications in space. For thermal insulating support straps, a high stiffness is very important, because such straps are sensitive for global and local buckling. A high stiffness reduces the cross-sectional area and thus reduces heat flow. Of course, the intrinsic thermal insulating properties of M5 are also an advantage in this respect.

4. Backing plates for satellite solar panels. The highstiffness combined with the electrical insulating properties of M5 make it possible to reduce production costs of satellite solar panels. The Kapton insulating layer between the solar cells and backing plate can be left out. The expensive inspection of this layer is thus also redundant.

5. Electrical insulating ladders. Ladders for use in electricity towers should also combine high stiffness and electrical insulating properties for obvious reasons.
6. Hockey sticks. A prototype of a full composite M5 hockey stick has been manufactured and field tested. It turned out to have excellent damping characteristics, making it very comfortable to play with. The low mass of the stick allowed very fast moves. The unique appearance is also a great advantage for sporting goods, e.g. hockey sticks, golf clubs and tennis rackets (Fig. 8).

7. Side Impact Protection Beams for cars. For this purpose, the performance of such beams in three-point bending is calculated for several engineering composites $\left(V_{\mathrm{f}}=\right.$ $60 \%$ ) and compared with test results for steel. It is a rectangular beam with a width of $50 \mathrm{~mm}$, a height of $30 \mathrm{~mm}$, a wall thickness of $2 \mathrm{~mm}$ and a length of $800 \mathrm{~mm}$. The lay-up for the composites is UD with the fibre direction parallel to the length of the beam. The absorbed energy $\left(E_{\text {abs }}\right)$ is the absorbed energy at the maximum load $\left(P_{\max }\right)$. The maximum deflection is indicated by $d_{\max }$. The results in Table 10 show excellent energy-absorbing capabilities of M5 compared to steel (column 6). Considerable weight savings (up to 50\%) can be achieved by using pull-truded UD M5 composite beams, compared to state-of-the-art steel. Some other remarks about Table 10 can be made:

a. The aramid beam will probably fail at the compressive side of the beam.

b. The M5 beam will probably fail at the tensile side of the beam. After failure, a considerable residual strength will be left (compare to Fig. 5).

Table 9

Summary of results of three-point bending tests according to ASTM D790M; fibre properties calculated with the Plastic Bending Theory

\begin{tabular}{|c|c|c|c|c|c|c|c|}
\hline $\begin{array}{l}\text { M5 batch } \\
\text { number }\end{array}$ & $\begin{array}{l}\text { Tensile/compr. } \\
\text { modulus (GPa) }\end{array}$ & $\begin{array}{l}\text { Compr. yield } \\
\text { stress }(\mathrm{MPa})\end{array}$ & $\begin{array}{l}\text { Compr. yield } \\
\text { strain }(\%)\end{array}$ & $\begin{array}{l}\text { Tensile stress at } \\
\text { failure }(\mathrm{MPa})\end{array}$ & $\begin{array}{l}\text { Tensile strain at } \\
\text { failure }(\%)\end{array}$ & $\begin{array}{l}\text { Compr. stress at } \\
\text { failure }(\mathrm{MPa})\end{array}$ & $\begin{array}{l}\text { Compr. strain at } \\
\text { failure }(\%)\end{array}$ \\
\hline 7 & $283 \pm 31$ & $1213 \pm 57$ & $0.45 \pm 0.06$ & $2436 \pm 192$ & $0.95 \pm 0.03$ & $1213 \pm 57$ & $1.23 \pm 0.11$ \\
\hline
\end{tabular}




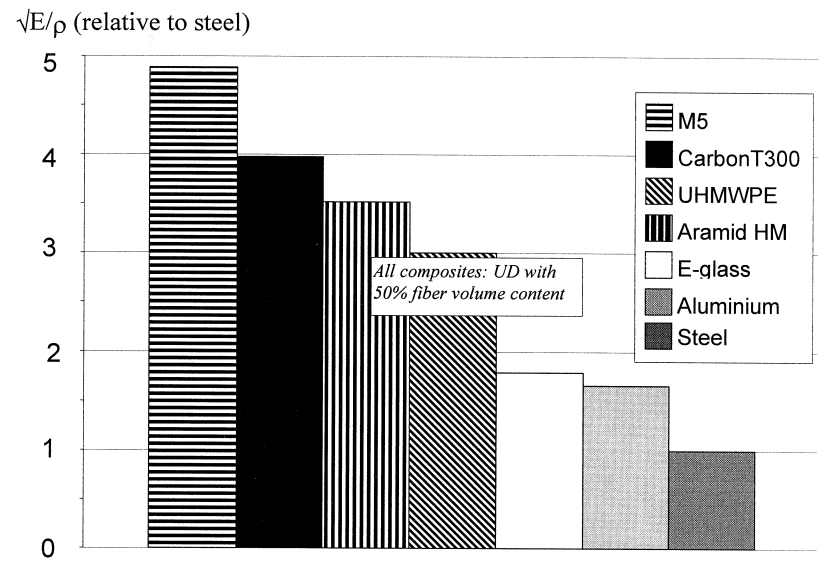

Fig. 7. Structural efficiency of several engineering materials in components critical for global buckling relative to that of steel.

c. In both cases, the beam will still be in one part when passing $P_{\max }$, though with little load carrying capabilities.

d. The carbon fibre beam will probably fail in a brittle manner. After reaching $P_{\max }$, the beam will be in two halves. It is not unlikely that the two halves, with very sharp edges, will enter the passenger compartment.

e. Even better results for the composite beams can be achieved by adding $\pm 45^{\circ}$ layers, which can carry shear loads more effectively than UD layers.

8. Fibre Metal Laminates. Another promising application is the use of M5 in Fibre Metal Laminates (FML). FML consist of thin plates of aluminium $(0.3 \mathrm{~mm})$ with crossply fibre/epoxy layers inbetween. Currently, aramid (FML: ARALL) or glass (FML: GLARE) fibres are used in these materials. A higher modulus of FML than achievable with the current fibres is desirable. This cannot be achieved by the use of carbon fibres, because of the danger of galvanic corrosion. M5 is in this case an interesting and promising option.

\section{Conclusions}

M5 is a new fibre material that outclasses most other engineering fibres. It can be used to create efficient and cost-effective structures.

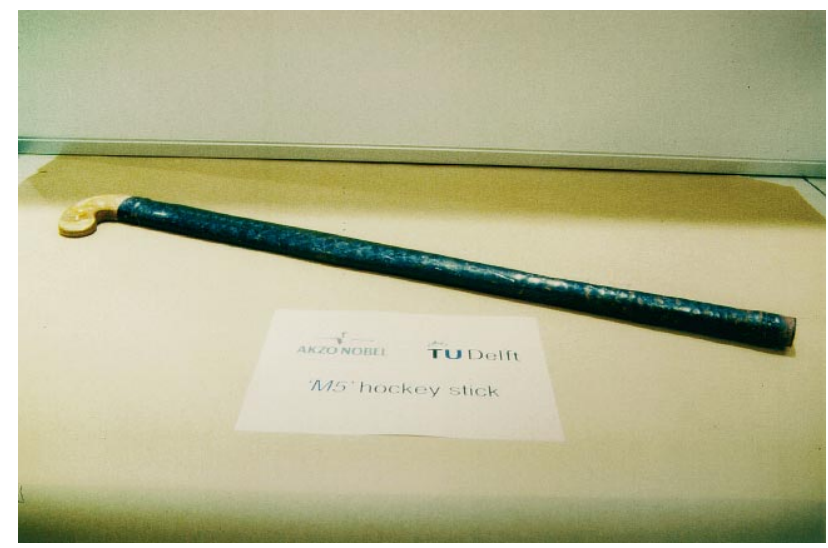

Fig. 8. Full composite M5 hockey stick.

Table 11

Compressive mechanical properties of M5

\begin{tabular}{ll}
\hline$E_{\mathrm{c}}$ & $330-350 \mathrm{GPa}$ \\
$\epsilon_{\mathrm{c}, \text { yield }}$ & $0.45-0.50 \%$ \\
$\epsilon_{\mathrm{c}, \max }$ & $0.9-1.2 \%$ \\
$\sigma_{\mathrm{c}, \max }$ & $1575-1750 \mathrm{MPa}$ \\
\hline
\end{tabular}

Table 11 shows a summary of M5 fibre compressive properties, derived from tests on UD M5/epoxy composites.

The material efficiency coefficient of a UD M5/epoxy composite $\left(50 \% V_{\mathrm{f}}\right)$ exceeds that of common carbon composites by $25 \%$. It exceeds the material efficiency of other polymeric and glass fibre composites by $30-200 \%$ and that of steel by $500 \%$. This is also valid for structures that carry compressive loads.

Due to the combination of high material efficiency coefficient, its thermal and electrical properties, and a relative high maximum strain level, compared with carbon fibres, M5 is suited for use in special products, for which carbon fibres cannot be used, or where the application of M5 offers a significant advantage. Some examples of such products are: LPG tanks, thermal insulating support struts for space applications, Side Impact Protection Beams for cars, and Fibre Metal Laminates.

M5 can also be used in any other product currently made with carbon fibre composites, except those which exploit the

Table 10

Results of three-point bending tests and calculations on a beam of equal dimensions $(50 \times 30 \times 2 \mathrm{~mm} ; L=800 \mathrm{~mm})$

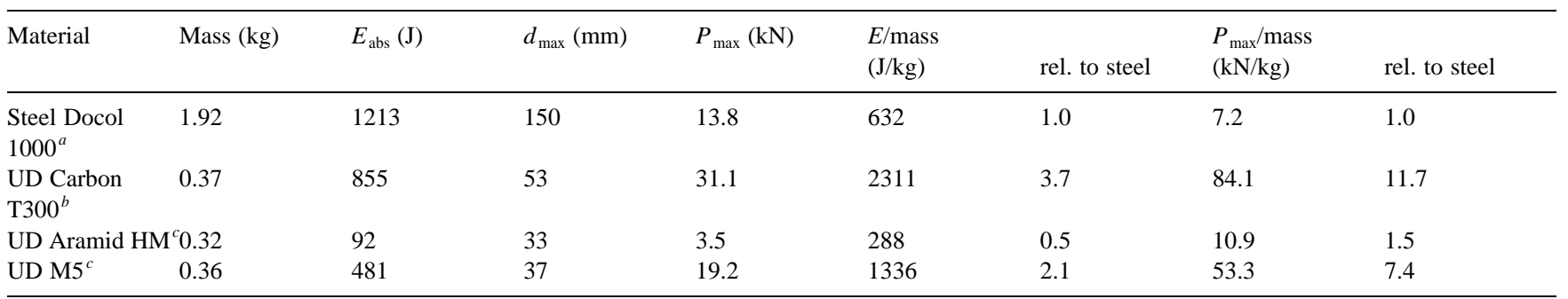

\footnotetext{
${ }^{a}$ Results from tests [4].

${ }^{b}$ Calculated with Linear Bending Theory.

${ }^{c}$ Calculated with Plastic Bending Theory.
} 


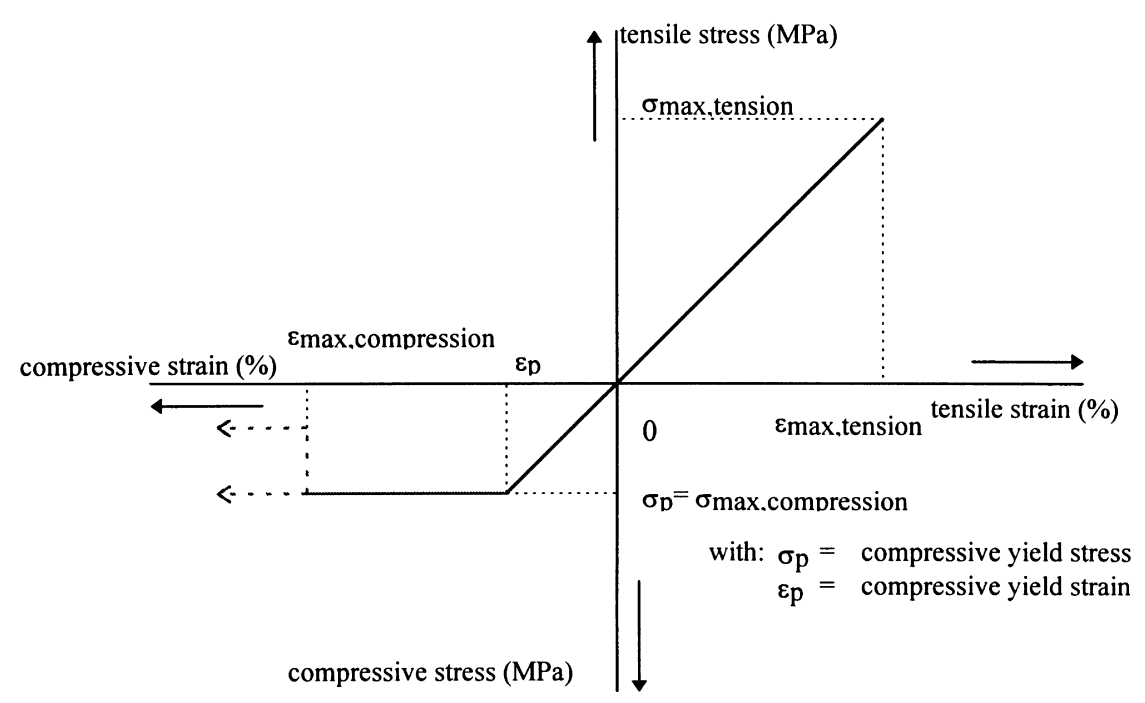

Fig. 9. Schematic stress-strain curve.

electrical and/or thermal conductivity of carbon fibres. These products involve amongst others hockey sticks and tennis rackets, sailing boats and parts for cars. The unique appearance of the M5 fibre is, besides its special mechanical and physical properties, a great advantage in this field.

\section{Appendix A Plastic Bending Theory}

The Plastic Bending Theory can be used to calculate compressive strains as a result from bending, beyond the compressive yield point in the stress-strain curve, of a material displaying ideal elastic/plastic behaviour.

\section{Appendix A.1 List of symbols}

$\epsilon_{\mathrm{c}}=$ compressive strain at surface

$\epsilon_{\mathrm{p}}=$ compressive yield strain

$\epsilon_{\mathrm{t}}=$ tensile strain at surface

$\sigma_{\mathrm{c}}=$ compressive stress at surface

$\sigma_{\mathrm{p}}=$ compressive yield stress

$\sigma_{\mathrm{t}}=$ tensile stress at surface

$d=$ specimen thickness

$y_{\mathrm{c}}=$ compressive surface

$y_{\mathrm{n}}=$ neutral axis

$$
\begin{aligned}
& y_{\mathrm{p}}=\text { plastic axis } \\
& y_{\mathrm{t}}=\text { tensile surface } \\
& E=\text { modulus of elasticity } \\
& M_{\mathrm{b}}=\text { bending moment }
\end{aligned}
$$

\section{Appendix A.2 Assumptions}

The Plastic Bending Theory makes the following assumptions (Fig. 9):

1. The modulus in compression equals the modulus in tension $\left(E_{\text {tension }}=E_{\text {compression }}=E\right)$.

2. The linear elastic parts of the stress-strain curve (both the tension and compression part) follow Hooke's law $\left(\sigma_{\text {tension }}=E \epsilon_{\text {tension }}\right.$ and $\left.\sigma_{\max \text {, compression }}=\sigma_{p}=E \epsilon_{p}\right)$.

3. There are no resulting forces in the fibre direction $(\Sigma N=0)$.

4. The internal bending moment resulting from internal tensile and compressive stresses equals the applied bending moment $\left(\Sigma M=M_{\mathrm{b}}\right)$.

Assumptions (3) and (4) lead to equilibrium equations.
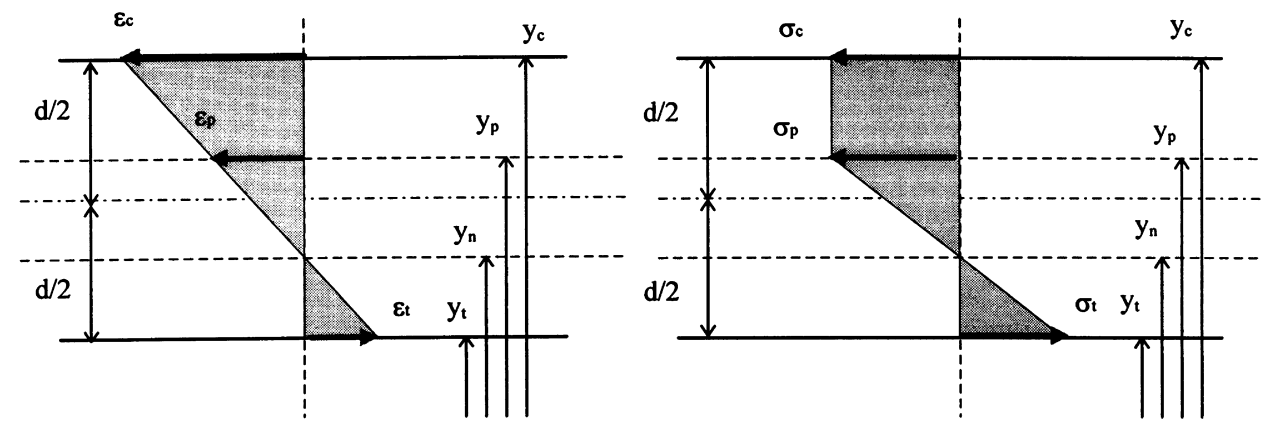

Fig. 10. Strain (left) and corresponding stress (right) distribution throughout the thickness of the specimen at an arbitrary point in the non-linear part of the stress-strain curve. 
At an arbitrary point in the non-linear part of the stressstrain curve, the stress and strain distribution over the thickness at the centre of the specimen look like Fig. 10, based on the previous assumptions.

Based on Fig. 10, the following equations for the neutral and plastic axis can be calculated:

$y_{\mathrm{n}}=\frac{\epsilon_{\mathrm{t}}}{\epsilon_{\mathrm{t}}-\epsilon_{\mathrm{c}}} d+y_{\mathrm{t}}$

$y_{\mathrm{p}}=\frac{\epsilon_{\mathrm{p}}-\epsilon_{\mathrm{t}}}{\epsilon_{\mathrm{c}}-\epsilon_{\mathrm{t}}} d+y_{\mathrm{t}}$

The assumptions lead to the following equations for the non-linear part of the force-displacement curve:

Assumptions (1) and (2):

$\sigma_{\mathrm{c}}=\sigma_{\mathrm{p}}=E \epsilon_{\mathrm{p}}$

$\sigma_{\mathrm{t}}=E \epsilon_{\mathrm{t}}$

Assumption (3):

$\epsilon_{\mathrm{t}}=\sqrt{\frac{\sigma_{\mathrm{c}}}{E}\left(2 \epsilon_{\mathrm{c}}-\frac{\sigma_{\mathrm{c}}}{E}\right)}$
Assumption (4) [with the aid of Eqs. A1-A5]:

$M_{\mathrm{b}}=\frac{d^{2}}{6\left(\epsilon_{\mathrm{c}}-\epsilon_{\mathrm{t}}\right)^{2}}\left\{\sigma_{\mathrm{p}}\left(3 \epsilon_{\mathrm{c}}^{2}-\epsilon_{\mathrm{p}}^{2}\right)-2 E \epsilon_{\mathrm{t}}^{3}\right\}$

With the maximum bending moment $\left(M_{\mathrm{b}}\right)$, thickness $(d)$, yield point $\left(\sigma_{\mathrm{p}}, \epsilon_{\mathrm{p}}\right)$, modulus $(E)$ and maximum tensile strain known $\left(\epsilon_{\mathrm{t}}\right)$, the maximum compressive strain $\left(\epsilon_{\mathrm{c}}\right)$ can be calculated with the aid of Eq. (A6).

\section{References}

[1] Tempelman E. Design for sustainability: The advent of hybrid materials. Proceedings of ISATA 29th International Symposium on Automotive Technology and Automation. Vol. I, Florence, June 1996:261-268.

[2] Welsh JS, Adams DF. Current status of compression test methods for composite materials. SAMPE Journal 1997;33(1):35-44.

[3] Beukers A. Polymer composites versus metals, the structural efficiencies compared. SAMPE Proceedings, Tokyo, 1991:1113-1120

[4] Sperle JO, Olsson K. High strength and ultra-high strength steels for weight reduction in structural and safety-related applications. Proceedings of ISATA 29th International Symposium on Automotive Technology and Automation. Vol. I, Florence, June 1996:115-125. 